\title{
Humidity-Sensitive Properties of Titania Films Prepared Using the Sol-Gel Process
}

\author{
Gualtiero GUSMANO, Giampiero MONTESPERELLI, Patrizia NUNZIANTE, Enrico TRAVERSA, \\ Angelo MONTENERO*, Marco BRAGHINI*, Giulia MATTOGNO** and Andrea BEARZOTTI*** \\ Dipartimento di Scienze e Tecnologie Chimiche, Università di Roma "Tor Vergata", Via della Ricerca Scientifica, 00133 Roma, Italy \\ *Istituto di Strutturistica Chimica, Università di Parma, Viale delle Scienze, 43100 Parma, Italy \\ ${ }^{* *}$ Istituto di Teoria e Struttura Elettronica, C.N.R., C.P. 10, 00016 Monterotondo Stazione, Roma, Italy \\ ***Istituto di Elettronica dello Stato Solido, C.N.R., Via Cineto Romano 42, 00156 Roma, Italy
}

\section{ゾル-ゲル法で作製した酸化チタン薄膜の感湿特性}

\section{Gualtiero Gusmano - Giampiero Montesperelli - Patrizia Nunziante - Enrico Traversa •} Angelo Montenero* - Marco Braghini* ${ }^{*}$ Giulia Mattogno** - Andrea Bearzotti***

Dipartimento di Scienze e Tecnologie Chimiche, Università di Roma “Tor Vergata”, Via della Ricerca Scientifica, 00133 Roma, Italy *Istituto di Strutturistica Chimica, Università di Parma, Viale delle Scienze, 43100 Parma, Italy

**Istituto di Teoria e Struttura Elettronica, C.N.R., C.P. 10, 00016 Monterotondo Stazione, Roma, Italy

***Istituto di Elettronica dello Stato Solido, C.N.R., Via Cineto Romano 42, 00156 Roma, Italy

$\mathrm{TiO}_{2}$ films, as well as powders as reference, were prepared using the sol-gel process, using titanium isopropylalkoxide (TIPT) as a precursor. The films were deposited on glass slides and heated either to $300^{\circ} \mathrm{C}$ or to $500^{\circ} \mathrm{C}$. The morphology of the film surface was observed using scanning electron microscopy (SEM). Fourier transform infrared (FTIR) spectroscopy, X-ray diffraction (XRD), X-ray photoelectron spectroscopy (XPS), and electrochemical impedance spectroscopy (EIS) at different relative humidities were carried out to study the possibility of using sol-gel processed titania films as detecting elements in humidity sensors. A good resistance versus relative humidity (rh) sensitivity was observed in the range from $50 \%$ to $85 \% \mathrm{rh}$. The response time of titania films was rather fast, estimated in a few seconds.

Key-words : Humidity sensors, Titania, Sol-gel, Film, Electrical properties

\section{Introduction}

Miniaturization of sensors is required for on-chip integration technology, which is becoming increasingly important in sensor production. ${ }^{1)}$ Fabrication technologies of microelectrodes, such as sputtering, chemical etching, thick- and thin-film preparations, have been used to develop various chemical sensors. ${ }^{2)}$ Ceramic materials are suitable for application to chemical sensors. ${ }^{3)}$

Recent progress in ceramic deposition technologies, mainly driven by the continuous advancement of microelectronics, provides new possibilities for development of ceramic active elements in the field of chemical sensors. The sol-gel method is very attractive for the preparation of very uniform ceramic powders, with high purity and a very homogeneous distribution of the components on the atomic scale. But probably its most promising feature is the possibility of powder-free processing of ceramics in their final shape, like fiber or film, ${ }^{4}$ which can be used as active elements in sensing devices. Another advantage which may be derived from the use of sol-gel processing in sensor manufacturing technology, is a deposition method less costly than the others currently used to produce ceramic films. Recently, studies on the application of the sol-gel technique to the production of optical(5)-7) and chemical ${ }^{8), 9)}$ sensing devices have been reported in the relevant literatures.

In the field of humidity sensors, more studies have been made of polymer films than of ceramic films. ${ }^{10)}$ Only a few ceramic oxides have been investigated in thin-film form, ${ }^{11)-13)}$ or in films prepared by sol-gel method. ${ }^{14), 15)}$ Several attempts have been made to develop microchip humidity sensors using integrated circuit technology, based on ceramic sensing elements. ${ }^{16)-20)}$

The use of either sintered porous compacts or thick films of titania and doped-titania as sensing elements for humidity-measurement devices has shown promise in the literature. ${ }^{21)-27)}$ This paper deals with the processing of $\mathrm{TiO}_{2}$ films using the sol-gel technique. Chemical, microstructural and electrical analyses were carried out in order to study the possibility of using titania films as detecting elements in a sensor device suitable for hybrid electronic integration.

\section{Experimental procedure}

\subsection{Materials}

Titanium isopropylalkoxide (TIPT) was used as the precursor compound for the sol-gel process. The starting solution was prepared by mixing TIPT (A1drich), isopropanol (Aldrich), distilled water and $\mathrm{HCl}(37 \%)$ as a catalyst, with molar ratios of $1: 21$ : 
1: 0.11 . The solution was stirred for $10 \mathrm{~min}$.

From this solution, bulk gels and films were obtained. The bulk was dried in an oven for one day at $100^{\circ} \mathrm{C}$, powdered, heated to different temperatures and then analyzed. The films were deposited on commercial glass microscope slides, previously carefully cleaned. The slides were dipped into the solution and withdrawn at a speed of $0.07 \mathrm{~cm} / \mathrm{min}$. The films were dried in an oven at $100^{\circ} \mathrm{C}$ for $30 \mathrm{~min}$. Afterwards, the samples were heated either to $300^{\circ} \mathrm{C}$ or to $500^{\circ} \mathrm{C}$, at a heating rate of $100^{\circ} \mathrm{C} / \mathrm{h}$ in an oven, and then were immediately allowed to cool to room temperature in the same oven. In order to study their electrical properties, gold electrodes $200 \mathrm{~nm}$ thick, $100 \mu \mathrm{m}$ wide and spaced $40 \mu \mathrm{m}$ apart, were deposited on the sensitive film by evaporation, and defined by a standard photolithographic process.

\subsection{Measurements}

In order to study the preparation procedure, the powders obtained from the bulk gels were studied by Fourier transform infrared (FTIR) spectroscopy (Nicolet model 5PC), X-ray diffraction analysis (XRD), performed with a Philips model PW 1050, using $\mathrm{Cu} \mathrm{K} \alpha$ radiation $(\lambda=0.154 \mathrm{~nm})$, and $\mathrm{X}$-ray photoelectron spectroscopy (XPS), using an Escalab Vacuum Generator (VG).

All X-ray photoelectron spectra were recorded in the fixed analyzer transmission (FAT) mode with a pass energy of $20 \mathrm{eV}$, using $\mathrm{Al} \mathrm{K} \alpha_{1,2}$ radiation as an excitation source $(h v=1486.6 \mathrm{eV})$. All measurements were performed at a residual pressure of $10^{-9}$ $\mathrm{Pa}$. The binding energy (b.e.) scale was calibrated using the $4 f_{7 / 2}$ gold signal at $83.7 \mathrm{eV}$. Corrections of the energy shift due to the steady-state charging effect of the samples were carried out by referencing to the $\mathrm{C} 1 \mathrm{~s}$ line (b.e. $=285.0 \mathrm{eV}$ ) from the residual pump-line oil contamination. The accuracy of the b.e. values measured was $\pm 0.2 \mathrm{eV}$, and the reproducibility of the results was within these values. The spectra were collected by a DEC PDP $11 / 83$ data system and data handling software provided by the spectrometer manufacturer (VG 5000 processing software).

The films were analyzed by XPS, by scanning electron microscopy (SEM; Jeol model 6300), and by electrochemical impedance spectroscopy (EIS), u.Sing a Solartron model 1255 frequency response analyzer equipped with a high impedance adaptor built by us. Impedance spectra were recorded in the frequency range from $10^{-2}$ to $10^{5} \mathrm{~Hz}$, at $40^{\circ} \mathrm{C}$, at relative humidity ( $\mathrm{rh}$ ) values ranging from $5 \%$ to $85 \%$. The resistance values were calculated on the complex plane plot from the intercepts of the semiarc at high frequencies, extrapolated where necessary, with the real axis. ${ }^{12)}$

Stability tests and response time measurements were also performed. EIS measurements over the entire rh range tested were repeated at different time intervals after keeping the specimens $12 \mathrm{~h}$ at $5 \% \mathrm{rh}$.
Response time tests were performed by measuring the current for $0.5 \mathrm{~V}$ dc potential application, during rh cycling, using a Keithley Quasistatic CV-meter 595.

\section{Results and discussion}

Figure 1 shows the typical morphology of the titania films heated to $500^{\circ} \mathrm{C}$. SEM observations showed that films were compact, free of porosity, made up of quite uniform particles less than $100 \mathrm{~nm}$ in diameter. The films heated to $300^{\circ} \mathrm{C}$ showed practically the same morphology. SEM observations confirmed that the films were about $0.3-0.4 \mu \mathrm{m}$ thick, as measured using a surface roughness meter. These thicknesses are in line with those reported in the literature for similarly prepared titania coatings. ${ }^{28)}$

Figure 2 shows the FTIR spectra of the powdered bulk gel, heated to different temperatures up to $500^{\circ} \mathrm{C}$. The large peak at $1000-400 \mathrm{~cm}^{-1}$ is attributa-

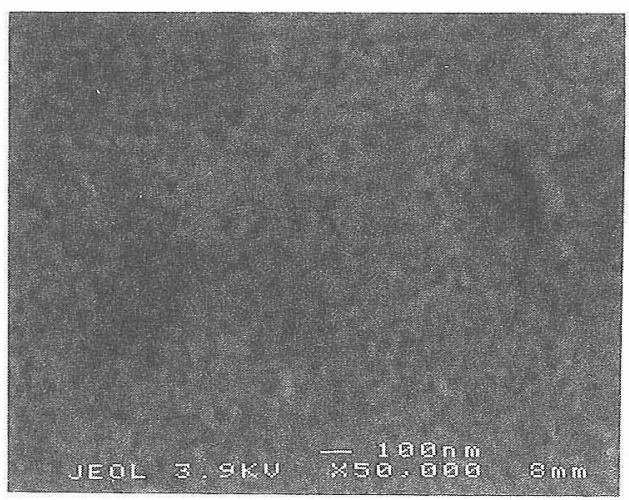

Fig. 1. SEM micrograph of the surface of the $\mathrm{TiO}_{2}$ film heated to $500^{\circ} \mathrm{C}$.

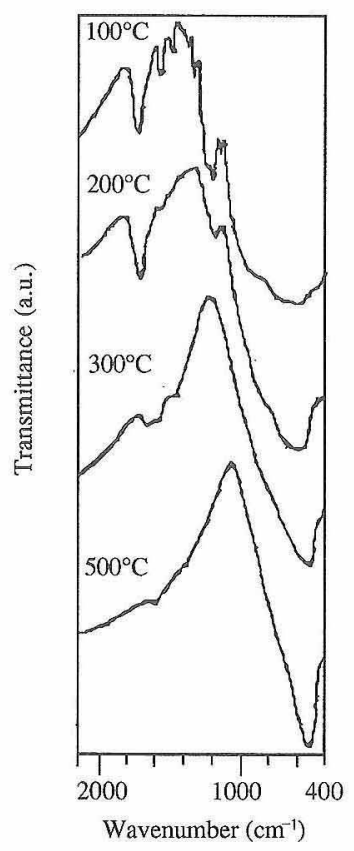

Fig. 2. IR spectra of $\mathrm{TiO}_{2}$ powders heated to different temperatures. 
ble to the Ti-O bond, according to the results reported in the literature. ${ }^{29)}$ All the other peaks are attributable to the organic compounds remaining in the gel. These peaks decrease in intensity with increasing temperatures, and they disappear when the temperature reaches $500^{\circ} \mathrm{C}$. The higher the temperature, the sharper the peak attributed to the Ti-O bond.

Figure 3 shows the XRD patterns of the powdered bulk gel, heated to different temperatures up to $500^{\circ} \mathrm{C}$. Below $200^{\circ} \mathrm{C}$, the diffraction patterns showed a lack of any definite structure. The anatase structure appears above $250^{\circ} \mathrm{C}$. Similar results have been reported by other authors for a gel with composition between $90 \%$ and $100 \%$ of $\mathrm{TiO}_{2}$ prepared with a similar method. ${ }^{30)}$ The crystallinity of the specimens increases with increasing temperatures, up to $500^{\circ} \mathrm{C}$ when the powder is fully crystalline. Raman spectroscopy investigations, carried out by some of the authors of this paper and reported elsewhere, ${ }^{31)}$ confirmed that the anatase phase is present and well formed already at $350^{\circ} \mathrm{C}$, showing a well-defined peak in the region $145-160 \mathrm{~cm}^{-1}$. Standard XRD analysis carried out on $\mathrm{TiO}_{2}$ films heated up to $500^{\circ} \mathrm{C}$ did not reveal any definite structure. However, XRD tests performed using very low scanning rate on films deposited on quartz substrate and heated to $900^{\circ} \mathrm{C}$, showed broad peaks of an oriented anatase structure. This may suggest a slower crystallization for $\mathrm{TiO}_{2}$ films than for $\mathrm{TiO}_{2}$ powdered bulks.

Table 1 shows the Ti $2 p$ and O1s binding energy (b.e.) values (in $\mathrm{eV}$ ) measured on both powders and films heated to $300^{\circ} \mathrm{C}$ and $500^{\circ} \mathrm{C}$. The analysis of the

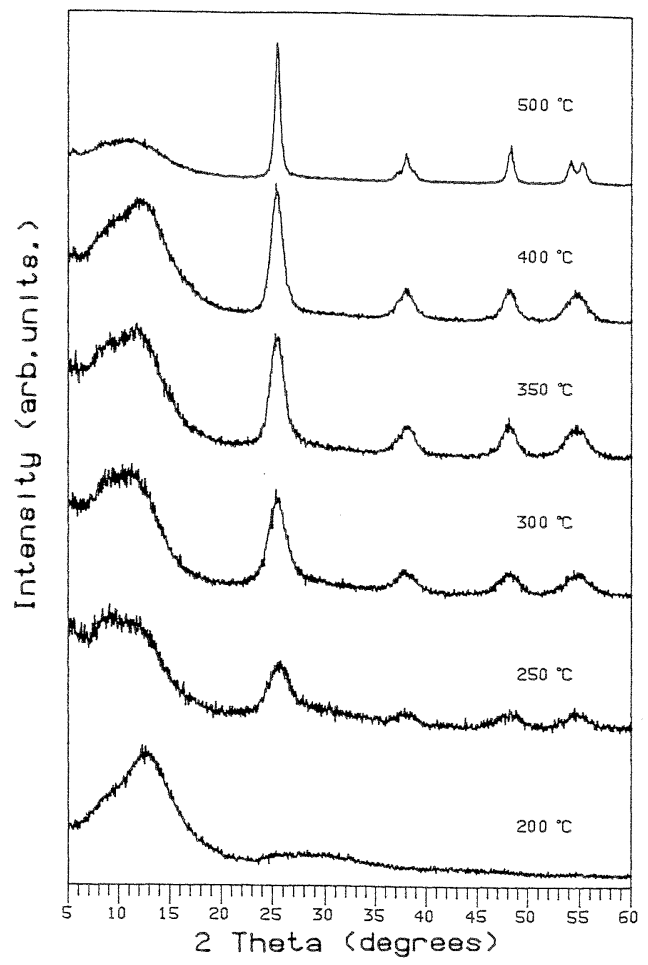

Fig. 3. XRD patterns of $\mathrm{TiO}_{2}$ powders heated to different temperatures.
Table 1. XPS binding energy ( $\mathrm{eV}$ ) for the specimens analysed, with quantitative percentage of the three components of the $\mathrm{O} 1 \mathrm{~s}$ line and FWHM of the Ti $2 \mathrm{p}$ line.

\begin{tabular}{cccccc}
\hline \multirow{2}{*}{ Specimen } & \multirow{2}{*}{$\mathrm{Ti} 2 p$} & & \multicolumn{3}{c}{$\mathrm{O} 1 \mathrm{~s}$} \\
\cline { 4 - 6 } & & (FWHM) & $\mathrm{TiO}_{2}$ & $-\mathrm{OH}$ & $\mathrm{H}_{2} \mathrm{O}$ \\
\hline powder $300^{\circ} \mathrm{C}$ & 458.5 & \multirow{2}{*}{1.84} & 530.0 & 531.2 & 532.3 \\
& & & $(78 \%)$ & $(14 \%)$ & $(8 \%)$ \\
powder $500^{\circ} \mathrm{C}$ & \multirow{2}{*}{458.9} & \multirow{2}{*}{1.65} & 530.2 & 531.8 & 532.6 \\
& & & $(82 \%)$ & $(9 \%)$ & $(9 \%)$ \\
film $300^{\circ} \mathrm{C}$ & \multirow{2}{*}{458.5} & \multirow{2}{*}{1.64} & 529.9 & 531.5 & 532.9 \\
& & & $(53 \%)$ & $(25 \%)$ & $(22 \%)$ \\
film $500^{\circ} \mathrm{C}$ & \multirow{2}{*}{458.5} & \multirow{2}{*}{1.51} & 529.7 & 531.4 & 532.6 \\
& & & $(62 \%)$ & $(22 \%)$ & $(16 \%)$ \\
\hline
\end{tabular}

Ti $2 p$ spectra of all the specimens shows b.e. values which are characteristic of the element in its $\mathrm{Ti}^{+4}$ oxidation state. ${ }^{32)}$ Table 1 also gives the full width at half maximum height (FWHM) values for the Ti $2 \mathrm{p}$ peak: one can observe that the width of the line increases with decreasing crystallinity in the specimens. However, the line widths are larger for the powdered specimens than for films. This can be explained in terms of the smoother surface of the films: the surface roughness of powdered specimens can produce different static charging effects which cause a broadening of the line width. ${ }^{33)}$

In the $\mathrm{O} 1 \mathrm{~s}$ region, all the specimens exhibited a complex band, for which curve fitting showed the presence of three components centered at b.e. values around 530, 531.5 and $532.6 \mathrm{eV}$ (Fig. 4). The first component is attributable to $\mathrm{TiO}_{2}$, in addition to a small part due to instrumental oxygen contamination. In fact, the quantitative $\mathrm{O} / \mathrm{Ti}$ ratios obtained by using this O1s component and the Ti $2 p$ line (between 2.1 and 2.3 for all the specimens) are close to the theoretical value. The components at $531.5 \mathrm{eV}$ and at $532.6 \mathrm{eV}$ are usually attributed to hydroxyl groups and to water molecules, respectively. ${ }^{34)}$ As shown in Table 1 , the quantities of the two components at higher b.e. values are larger for samples heated to $300^{\circ} \mathrm{C}$ and for films than for powders. The presence of a larger amount of water and of more hydroxyl groups in films than in powders may be at-

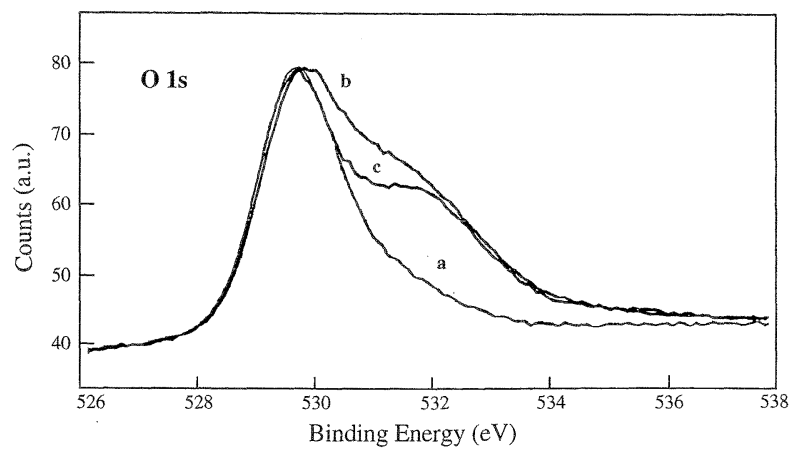

Fig. 4. XPS O1s peaks of the powder heated to $500^{\circ} \mathrm{C}$ (a), of the film heated to $300^{\circ} \mathrm{C}(\mathrm{b})$, and of the film heated to $500^{\circ} \mathrm{C}$ (c). 
tributed to the drying times of the specimens, which were $30 \mathrm{~min}$ for films and 1 day for powders. Also the crystallinity of the samples has to be considered, given that the less ordered the sample, the larger the number of water molecules and hydroxyl ions. XPS analysis performed on the films left in the test chamber for 1 day showed a decrease in the intensities of the two components of the O1s line at higher b.e. values, confirming the attribution made.

EIS spectra collected on films at rh values lower than about 30\% showed one inclined semicircle, which did not start from the origin of the complex plane axes. At higher rh, EIS spectra also showed another inclined semicircle at low frequencies, as shown in Fig. 5, where the complex impedance spectrum of the film heated to $500^{\circ} \mathrm{C}$ at $85 \%$ rh is reported. Therefore, the equivalent circuit model of titania films can be assumed to be made up of three elements in series: one resistive and two RC elements. In accordance with the findings of other authors, ${ }^{24)}$ the resistive element, which is independent of $r$, is characteristic of the bulk. It was measured to be about $10 \mathrm{k} \Omega$. The RC element at higher frequencies, which is rh-dependent, is characteristic of the grain surface. Given the generally accepted ionic conduction mechanism for ceramic oxides in humid environments, ${ }^{10)}$ the observed decrease in resistance with increasing rh is due to the increasing number of water molecules present on the surface. The RC element at low frequencies, which also depends on $\mathrm{rh}$, is attributable to polarization effects at the film-electrode interface. This effect occurs because gold electrodes are blocking for mobile conduction ions, which accumulate at the electrode interface when the number of carriers arriving at or departing from the electrode is too large to be kept up by the electrode reactions. ${ }^{24)} \mathrm{We}$ observed that this polarization effect depends on the geometry of the electrodes and the materials used. With the geometry adopted in our tests and the use of sputtered gold electrodes, polarization at the highest rh was much lower than that showed in similar conditions by spinel thin-films

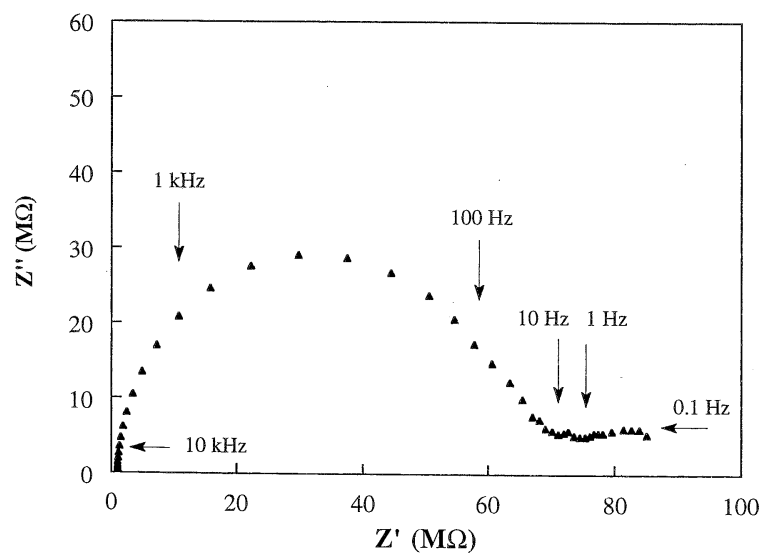

Fig. 5. Complex impedance plot of the $\mathrm{TiO}_{2}$ film heated to $500^{\circ} \mathrm{C}$, at $85 \% \mathrm{rh}$.

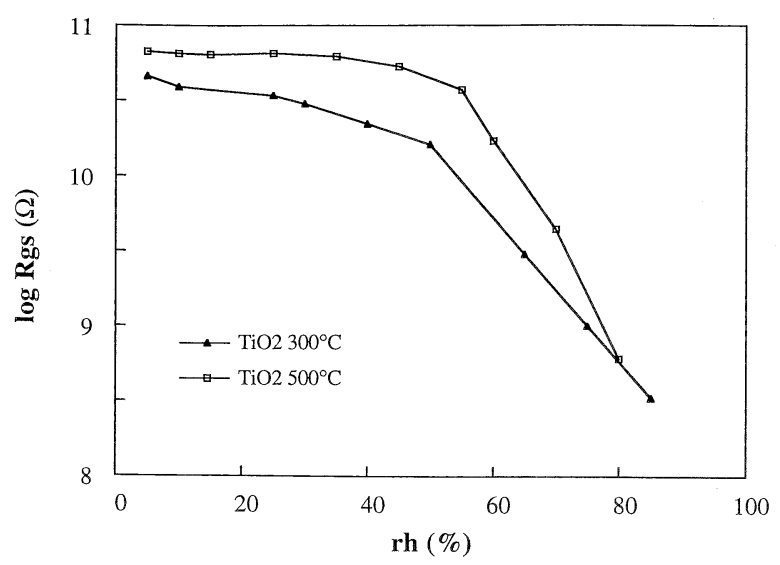

Fig. 6. Rh-dependence of titania films resistance at $40^{\circ} \mathrm{C}$.

with chromium electrodes. ${ }^{13)}$

Figure 6 shows the rh-dependence of resistance for titania films heated to $300^{\circ} \mathrm{C}$ and $500^{\circ} \mathrm{C}$. Both specimens showed similar behaviour: a small resistance variation from $0 \%$ to about $50 \% \mathrm{rh}$, and a good resistance versus rh sensitivity, of two orders of magnitude, in the range from $50 \%$ to $85 \% \mathrm{rh}$, with a good exponential relationship. The resistance of the specimens heated to $500^{\circ} \mathrm{C}$ is higher than that of specimens heated to $300^{\circ} \mathrm{C}$ over the entire rh range.

The rh-dependence of electrical conductivity for ceramic oxides has been widely recognized as related to the water adsorption mechanism on the surface of the oxides. ${ }^{10)}$ At low rh, conduction is due to proton hopping between hydroxyl ions on the first layer of chemisorbed water, whereas at high rh protons hop between physisorbed water molecules. Protons may arise from dissociation of hydroxyls and of water. The activation energy required to dissociate hydroxyl ions is higher than that needed to dissociate water molecules, thereby resulting in higher resistivity at low $\mathrm{rh}$. At high $\mathrm{rh}$, a higher carrier concentration is found when more than one layer of physisorbed water molecules is present on the oxide surface. These molecules are singly bonded and form a liquid-like network, which greatly increases the dielectric constant. ${ }^{35)}$ The increased dielectric constant promotes dissociation by lowering dissociation energy, which thus causes the increase in proton concentration. ${ }^{36)}$ Thus, the lack of sensitivity at low rh values is related to the microstructural features of the specimens. When the surface area is small, as for dense films, the number of adsorbed water molecules is also very small. This may explain the relationship between rh variations and the logarithm of the resistance observed for sol-gel processed titania films. This explanation has, in fact, already been given for a similar trend observed for dense $\mathrm{MgAl}_{2} \mathrm{O}_{4}$ thin-films. ${ }^{37)}$ Better sensitivities at low rh were observed for porous pellets of $\mathrm{MgAl}_{2} \mathrm{O}_{4}$ with a wide pore-size distribution by some of the authors of this 
paper. ${ }^{38)}$ Also in the case of porous titania pellets, the results of other authors ${ }^{22}$ ) have shown that the presence of porosity guarantees a better sensitivity at low rh. However, it must be kept in mind that, at low rh, impedance values of the same order of magnitude as the instrumental input impedance $\left(10^{11} \Omega\right)$ were recorded. The very high resistivity values measured may make them not entirely reliable.

Higher resistance values were measured on the films heated to $500^{\circ} \mathrm{C}$. Although both films have shown similar microstructures at SEM observations and are both rather dense, a decrease in the amount of adsorbed water may explain the higher resistivity of the films heated to $500^{\circ} \mathrm{C}$. In fact, the higher firing temperature of the films causes the more ordered structure of the films heated to $500^{\circ} \mathrm{C}$, accompanied by a decrease in their surface area and by a shift of average pore size towards larger values, and may be responsible for the lower number of hydroxyl ions and water molecules initially present on their surface, as demonstrated by XPS analysis, particularly at low rh. Less water can be adsorbed by these samples, resulting in higher resistivity over the entire rh range.

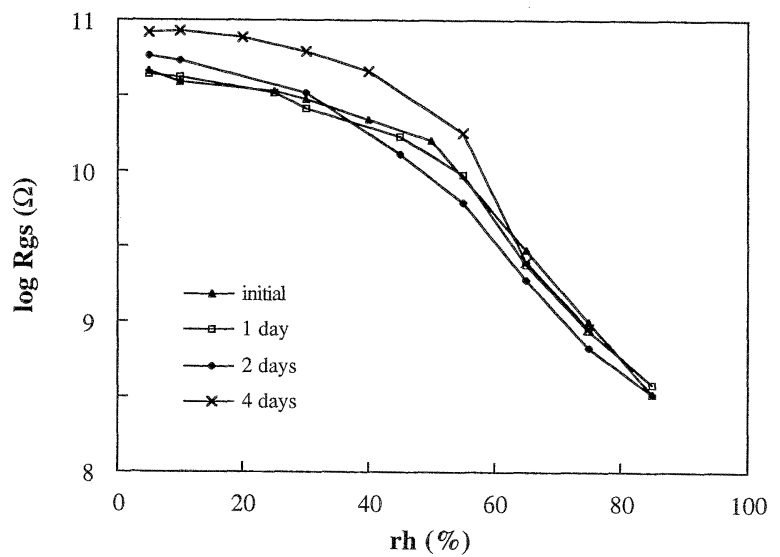

Fig. 7. Log resistance versus rh curves for the film heated to $300^{\circ} \mathrm{C}$, measured at different time intervals.

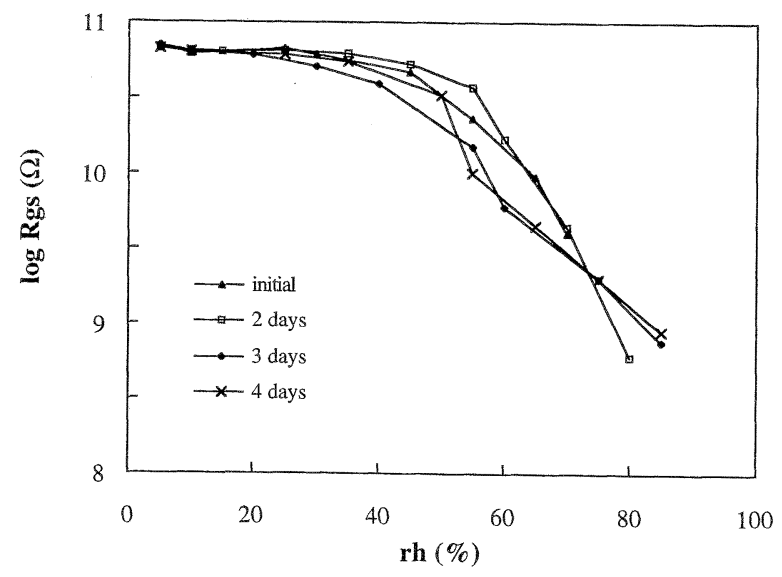

Fig. 8. Log resistance versus rh curves for the film heated to $500^{\circ} \mathrm{C}$, measured at different time intervals.

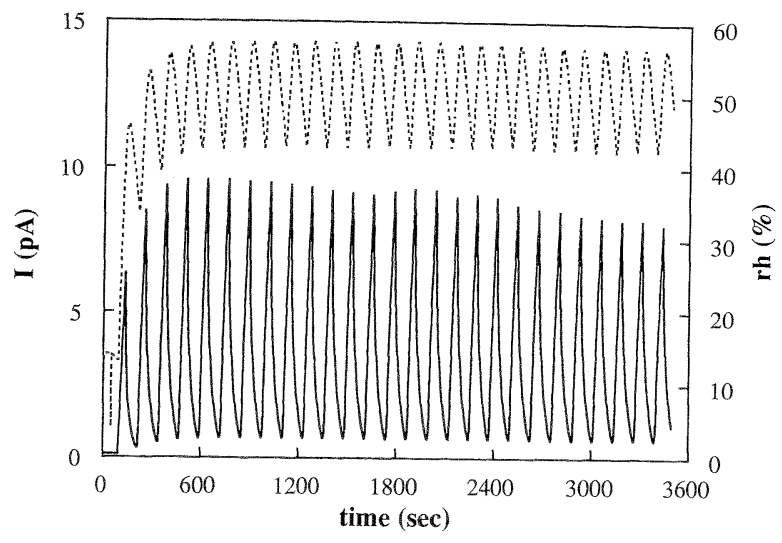

Fig. 9. Effect of rh cycling on the current response of the film heated to $300^{\circ} \mathrm{C}$, solid line for $I$ and dotted line for rh.

Reproducibility tests were performed by maintaining the films for $12 \mathrm{~h}$ at $5 \% \mathrm{rh}$ before each cycle of EIS measurements over the rh range tested. As shown in Figs. 7 and 8, the films heated to $300^{\circ} \mathrm{C} \mathrm{ex}$ hibit better reproducibility at $\mathrm{rh}$ values higher than $50 \%$, while films heated to $500^{\circ} \mathrm{C}$ behave better at rh lower than $50 \%$. These results may also be related to XPS findings: the films heated to $300^{\circ} \mathrm{C}$ have a tendency at low rh to loose some of the water molecules initially present. The films heated to $500^{\circ} \mathrm{C}$ may tend at high $\mathrm{rh}$ to have an increased number of water molecules more strongly bonded to the surface.

These results indicate that a proper activation treatment is necessary to improve the $\mathrm{TiO}_{2}$ film's electrical behaviour, both in terms of sensitivity and reproducibility over the entire rh range.

Response time measurements showed that $\mathrm{TiO}_{2}$ films respond promptly to a cyclic variation of $\mathrm{rh}$. The estimated response time is only a few seconds. After an initial drift, good reversibility and stability are observed (Fig. 9).

\section{Conclusions}

Their electrical characteristics make $\mathrm{TiO}_{2}$ films prepared using the sol-gel process candidates for use as sensing elements in humidity-measurement devices. Their exponential response at rh higher than about $50 \%$ and their short response time support this conclusion. Their high resistivity and their lack of sensitivity at low rh are, however, significant problems which are still to be resolved. These problems can probably be overcome by doping and by a suitable activation process. It seems extremely important to emphasize that doping can easily be carried out using the sol-gel preparation method.

Acknowledgments The authors thank Dr. G. Righini (CNR, ESCA Laboratory, Research Area of Rome) for technical assistance in providing XPS spectra.

This work was supported by the Italian National Research Council (CNR), under the auspices of the Targeted Project "Special Materials for Advanced Technologies." 


\section{References}

1) S. C. Chang and W. H. Ko, "Sensors: A Comprehensive Survey”, Ed. by W. Göpel, J. Hesse and J. N. Zemel, VCH, Weinheim (1989) pp. 169-94.

2) C. C. Liu, Techn. Dig. of 4th Intern. Meet. on Chemical Sensors, Tokyo, Japan, Sept. 13-17, 1992, Japan Ass. of Chemical Sensors, pp. 2-5.

3) J. Arndt, "Sensors: A Comprehensive Survey", Ed. by W Göpel, J. Hesse and J. N. Zemel, VCH, Weinheim (1989) pp. 248-78.

4) . J.C. Brinker and G. W. Scherer, "Sol-Gel Science", Academic Press, San Diego (1990) pp. 839-80.

5) V. Chernyak, R. Reisfeld, R. Gvishi and D. Venezky, Sens. Mater., 2, 117-26 (1990).

6) A. J. Martin and M. Green, Proc. SPIE-Int. Soc. Opt. Eng., 1328, 352-63 (1990).

7) K. T. V. Grattan, G. E. Badini, A. W. Palmer and A.C.C. Tseung, Sens. Actuators A, A26, 483-87 (1991).

8) G. C. Frye, J. C. Brinker, A. J. Ricco, S. Martin, J. Hilliard and D. H. Doughty, Mater. Res. Soc. Symp. Proc., 180, 58393 (1990)

9) J. I. Dulebohn, S. C. Haefner, K. A. Berglund and K. R. Dunbar, Chem. Mater., 4, 506-08 (1992).

10) B. M. Kulwicki, J. Am. Ceram. Soc., 74, 697-708 (1991).

11) Y. Nabeta, K. Suzuki and T. Inuzuka, "Chemical Sensors", Ed. by T. Seiyama, K. Fueki, J. Shiokawa and S. Suzuki, Kodansha, Tokyo and Elsevier, Amsterdam (1983) pp. 410-15.

12) G. Gusmano, G. Montesperelli, E. Traversa, A. Bearzotti, A. D'Amico and C. Di Natale, Sens. Actuators B, B7, 460-63 (1992).

13) G. Gusmano, G. Montesperelli, E. Traversa and G. Mattogno, J. Am. Ceram. Soc., 76, 743-50 (1993).

14) N. Yoshimura, S. Sato, M. Itoi and H. Taguchi, Sozai Busseigaku Zasshi, 3, 47-56 (1990).

15) G. Vaivars, J. Pitkevics and A. Lusis, Techn. Dig. of 4th Intern. Meet. on Chemical Sensors, Tokyo, Japan, Sept. 1317, 1992, Japan Ass. of Chemical Sensors, pp. 128-31.

16) M. G. Kovac, D. Chieck and P. Goodman, Solid State Technol., 21, 35-39 (1978).

17) P. P. L. Regtien, Sens. Actuators, 2, 85-95 (1981/82).

18) R. S. Jachowicz and S. D. Senturia, Sens. Actuators, 2, 171$86(1981 / 82)$.

19) S. L. Garverick and S. D. Senturia, IEEE Trans. Electron Devices, ED-29, 90-94 (1982).
20) M. Parameswaran, H. P. Baltes, M. J. Brett, D. E. Fraser and A. M. Robinson, Sens. Actuators, 15, 325-35 (1988).

21) K. Katayama, T. Akiba and H. Yanagida, "Chemical Sensors”, Ed. by T. Seiyama, K. Fueki, J. Shiokawa and S. Suzuki, Kodansha, Tokyo and Elsevier, Amsterdam (1983) pp. 433-38.

22) Y. C. Yeh, T. Y. Tseng and D. A. Chang, J. Am. Ceram Soc., 72, 1472-75 (1989).

23) T. Yamamoto and K. Murakami, "Chemical Sensor Technology, Vol. 2”, Ed. by T. Seiyama, Kodansha, Tokyo and Elsevier, Amsterdam (1989) pp. 133-49.

24) Y. C. Yeh, T. Y. Tseng and D. A. Chang, J. Am. Ceram. Soc., 73, 1992-98 (1990).

25) K. Katayama, K. Hasegawa, T. Takahashi, T. Akiba and H. Yanagida, Sens. Actuators A, A24, 55-60 (1990).

26) K. Katayama, K. Hasegawa, T. Noda, T. Akiba and H. Yanagida, Sens. Actuators B, B2, 143-49 (1990).

27) K. Katayama, K. Hasegawa, H. Osawa, T. Akiba and H. Yanagida, Sens. Mater., 2, 57-66 (1990).

28) M. Guglielmi, P. Colombo, L. Degli Esposti and G. Mancinelli, J. Mater. Sci., 27, 5052-56 (1992).

29) The SADTLER Standard Spectra, SADTLER Lab. Inc., Y249K (1967).

30) J. Cheng and D. Wang, J. Non-Cryst. Solids, 100, 288-91 (1988).

31) D. Bersani, P. P. Lottici, M. Braghini and A. Montenero, Phys. Stat. Sol. (b), 170, k5-k10 (1992).

32) C. D. Wagner, "Practical Surface Analysis by Auger and XRay Photoelectron Spectroscopy”, Ed. by D. Briggs and M. P. Seah, Wiley, London (1983) App. 4.

33) P. Swift, D. Shuttleworth and M. P. Seah, "Practical Surface Analysis by Auger and X-Ray Photoelectron Spectroscopy", Ed. by D. Briggs and M. P. Seah, Wiley, London (1983) App. 2.

34) E. Paparazzo, J. L. Dormann and D. Fiorani, Phys. Rev. B 28, 1154-57 (1983)

35) E. McCafferty and A. C. Zettlemoyer, Discuss. Faraday Soc. 52, 239-63 (1971).

36) J. H. Anderson and G. A. Parks, J. Phys. Chem., 72, 3362 68 (1968)

37) G. Gusmano, G. Montesperelli, E. Traversa and A. Bearzotti, Sens. Actuators B, B14, 525-27 (1993).

38) G. Gusmano, G. Montesperelli, P. Nunziante and E. Traversa, Br. Ceram. Trans. J. (1993) in press. 